Bryn Mawr College

Scholarship, Research, and Creative Work at Bryn Mawr

College

Psychology Faculty Research and Scholarship

Psychology

2004

\title{
Coming home upset: Gender, marital satisfaction and the daily spillover of workday experience into couple interactions
}

Marc S. Schulz

mschulz@brynmawr.edu

Philip A. Cowan

C.P. Cowan

Robert T. Brennan

Let us know how access to this document benefits you.

Follow this and additional works at: http://repository.brynmawr.edu/psych_pubs

Part of the Psychology Commons

\section{Custom Citation}

Schulz, M.S., Cowan, P.A., Cowan, C.P., \& Brennan, R. T. (2004). Coming home upset: Gender, marital satisfaction and the daily spillover of workday experience into marriage. Journal of Family Psychology 18, 250-263.

This paper is posted at Scholarship, Research, and Creative Work at Bryn Mawr College. http://repository.brynmawr.edu/psych_pubs/21

For more information, please contact repository@brynmawr.edu. 
Running head: Coming home upset

Schulz, M.S., Cowan, P.A., Cowan, C.P., \& Brennan, R. T. (2004). Coming home upset:

Gender, marital satisfaction and the daily spillover of workday experience into marriage.

Journal of Family Psychology, 18, 250-263.

Coming home upset: Gender, marital satisfaction and the daily spillover of workday experience into couple interactions

Marc S. Schulz

Bryn Mawr College

Philip A. Cowan

Carolyn Pape Cowan

University of California, Berkeley

Robert T. Brennan

Harvard University 
Coming home upset: Gender, marital satisfaction and the daily spillover of workday experience into couple interactions

\begin{abstract}
This study explored how daily changes in workday pace and end-of-the-workday mood were related to nightly variations in withdrawn and angry marital behavior. For 3 days, 82 husbands and wives from 42 couples completed questionnaires at the end of the workday and at bedtime. More negatively arousing workdays were linked with angrier marital behavior for women and less angry and more withdrawn behavior for men. Daily changes in workday pace predicted fluctuations in women's, but not men's, marital behavior. Several of these workday-marital behavior connections varied by level of marital satisfaction. In contrast to the gender differences in responses to workday stress, no differences were found in typical marital behaviors. These findings suggest that gender differences are enhanced under stress.
\end{abstract}


The evening interactions of couples with young children typically take place after both parents have experienced a day filled to varying degrees with working outside the home, taking care of children, and completing household chores and errands. These daily experiences are likely to set in motion a pattern of demands, stresses and frustrations that shape men's and women's emotional lives and the nature of their family relationships (Larson \& Richards, 1994). Surprisingly little is known about how these daytime emotional currents actually affect evening marital behaviors, and whether these effects are the same for men and women. In the present research, we explored this question using data from an intensive, short-term longitudinal study of 82 husbands and wives who are parents of young children.

Our primary aim was to explore how daily changes in workday pace and end-of-theworkday mood are connected to nightly variations in withdrawn and angry marital behavior. By exploring the emotion spillover processes that may underlie these connections, we seek to build upon and extend previous research and theoretical perspectives that focus on reactivity to negative emotions within marriage and the spillover of individual partners' emotions into the marital relationship (e.g., Crouter, Perry-Jenkins, Huston, \& Crawford, 1989; Gottman \& Levenson, 1988; Repetti, 1989). We also seek to add an important empirical perspective to ongoing questions about gender differences in coping and behavior in intimate relationships. While popular stereotypes and books (e.g., Gray, 1992; Tannen, 1990) suggest that there are strong and consistent differences in how men and women typically behave in intimate relationships, careful reviews of relevant research conclude that gender differences are often modest in magnitude and may be present only in certain contexts (e.g., Aries, 1996; Brody, 1999). Past research suggests that gender differences may be enhanced under conditions of stress or when individuals are experiencing negative emotions (Gottman \& Levenson, 1988; Taylor, 2002; Taylor et al., 2000). In the present study, we evaluate these perspectives by considering two distinct questions about men's and women's withdrawn and angry marital behaviors. We explore how stress or negative emotion from the workday might shape these behaviors and we investigate whether aggregated reports of nightly withdrawn and angry marital behaviors indicate that men and women typically act differently in marital interactions. Finally, in an 
attempt to clarify further how context influences men's and women's relationship behaviors, we also explore how differences in marital quality relate to men's and women's typical marital behaviors and their behaviors when they are under stress.

\section{Gender and Marital Behavior}

There are both personality-based and role-based factors that might underlie potential gender differences in withdrawn and angry marital behaviors. Laboratory-based observational research of couple interactions has provided evidence for both stable gender differences in marital behaviors and differences in the ways husbands and wives tend to respond to negative emotional arousal in their interactions (e.g., Gottman, 1994; Sagestrano, Heavey, \& Christensen, 1998). Husbands are generally more likely to withdraw emotionally and behaviorally from marital interactions, whereas wives are more likely to be verbally confronting, critical, and conflict engaging (Christensen \& Heavey, 1990; Gottman \& Levenson, 1998). Brody (1999) notes that marriage is one context in which women tend to express more anger (at least verbally) than men. These gender differences appear to be more pronounced when spouses experience negative affect, suggesting that these gender patterns may be more apparent under stress. Gottman and Levenson (1988) have argued that men's greater discomfort with the experience of negative emotion and its accompanying physiological arousal underlies the tendency of husbands to withdraw and wives to pursue.

Others have speculated that differences in goals in intimate relationships or in coping may underlie these gender patterns in behavior (e.g., Brody, 1999; Timmers, Fischer, \& Manstead, 1998; Taylor, 2002). Women are believed to be motivated to a stronger degree than men by affiliative goals that draw them closer to others when under stress. In a recent review, Taylor and colleagues (2000) concluded that, "Research on human males and females shows that, under conditions of stress, the desire to affiliate with others is substantially more marked among females than among males. In fact, it is one of the most robust gender differences in adult human behaviors" (p. 418). How might these differences in the desire for affiliation under stress influence the marital behaviors under consideration in this study? Two contradictory hypotheses each appear reasonable. First, and most obviously, this perspective suggests that women would be less likely than men to withdraw from marital interactions when stressed. Women may also 
make attempts to reduce their angry marital behavior in an attempt to connect with their partner when stressed. On the other hand, it is possible that greater engagement in marital interactions when stressed, regardless of the motivation, may be accompanied by an increase in negative and angry behaviors that are congruent with the negative emotions accompanying stress.

Another line of research on gender-based differences in men's and women's responses to negative mood states supports the latter hypothesis. Nolen-Hoeksema $(1987,1991)$ suggests that women are more likely than men to focus on their negative affective states and talk about their distress, whereas men are more likely to attempt to suppress or ignore their emotional arousal. The overall effect of rumination is to sustain or amplify the initial mood state, which would increase the likelihood of negative affect from the workday spilling into family interactions in the form of negative behaviors.

Men's and women's responses at home to difficult workday experiences, especially workday overloads, may also be influenced by differences in their family roles (Almeida \& Kessler, 1998). Despite dramatic increases in participation in the paid labor force, women have continued to bear a significantly larger share of household and child care responsibilities than men(Cowan \& Cowan, 1988; Hochshild, 1989). A role conflict perspective, which has shaped much of the research investigating workday-family linkages (e.g., Allen, Herst, Bruck, \& Sutton, 2000), suggests that a heavy workload outside the home can interfere with individuals' marital role obligations and alter marital behavior by reducing the amount of time and energy available to spend each evening as a marital partner and family member. Greater family demands may leave women particularly vulnerable to increases in daytime workload since it may challenge their capacity to balance high demands in both domains.

\section{Research on the Spillover of Workday Affective Experience into Marriage}

Negative emotions displayed in laboratory-based marital research are presumed to arise primarily from the interaction being observed between spouses at that moment. In the current study, we focus on an important question that has received less attention: How does negative affect and stress from the workday shape marital interactions at home each night? Researchers investigating these questions have typically employed traditional cross-sectional designs to compare the marital lives of individuals who experience high levels of workday stress with those 
who experience less stress. These studies, which analyze variation between subjects at a single point in time, suggest that more highly stressed individuals differ from their less stressed counterparts on the two dimensions we are interested in: They are more withdrawn and they are more likely to act in angry or aggressive ways towards other family members (e.g., Barling, 1990; Repetti, 1987). While these studies suggest that the marital lives of stressed workers differ from their less stressed counterparts, they tell us little about the psychological processes that may be responsible for the connections or whether those processes operate on a daily or longer-term basis. Furthermore, because of the cross-sectional design, it is difficult to ascertain the direction of influence between workday experience and family interactions.

Similar limitations characterize a second cross-sectional approach used to study daily connections between workday experiences and marital functioning. Studies in this tradition have examined the association between levels of perceived spillover or role conflict and measures of marital functioning (e.g., Hughes, Galinsky, \& Morris, 1992). Typically, participants are asked to estimate the degree to which job experiences influence their behavior at home. One concern in such studies is that estimates of spillover or role conflict may be distorted due to social desirability biases and memory and perceptual limitations inherent in trying to report on a complex phenomenon with negative connotations.

Longitudinal designs have been employed to study connections between work and marital life. However, the time lags between assessments in these studies are typically long -- on the order of months or years (e.g., Brennan, Barnett, \& Gareis, 2001) -- which makes it difficult to gather direct information about short-term processes such as affective spillover that are the focus of the present study.

Researchers have begun to employ repeated daily assessments of daytime and evening experiences and a within-subject data analytic approach to investigate the transmission of affective experience across settings or between family members (Larson \& Almeida, 1999; Repetti, 1989; 1994). This methodological strategy, commonly referred to as a daily diary approach, has four advantages for understanding daily workday experience, marital behavior, and the daily links between these two domains (Larson \& Almeida, 1999). First, assessing workday and family experiences close to the time they occur reduces retrospective reporting biases that 
typically arise when participants are asked to recall past experiences (Smith, Leffingwell, \& Ptacek, 1999). Second, daily measures can reduce social desirability biases by asking participants to focus on discrete negative behaviors in a limited time period (e.g., I criticized my wife tonight) rather than asking participants to characterize the degree to which a behavior is part of an enduring "trait" (e.g., I always criticize my wife). These two methodological advantages also make it likely that aggregating repeated daily assessments will yield more accurate reports of "typical behavior" than global queries that ask participants to characterize their typical behaviors over several days or weeks (Smith, Leffingwell, \& Ptacek, 1999). Third, repeated measures designs allow for the examination of covariation within persons, over time, of key variables such as workday stress and evening marital behaviors. Fourth, by including appropriate measures of, or controls for, hours worked, perceived workload, and negative affective experience, repeated measures designs can help to distinguish among affect spillover and role conflict processes.

Two studies have combined a repeated measures design with a within-subject data analytic approach to provide evidence that workday experiences influence nightly marital interactions (Bolger et al., 1989; Repetti, 1989). Repetti (1989) studied 33 male air traffic controllers (ATCs) over 3 days and found that the ATCs were more withdrawn and less angry on nights when they reported having had more difficult or busier workdays. Interestingly, analyses incorporating ATCs' bedtime reports of their mood after work did not alter the study's primary results. This additional set of analyses suggests that processes other than emotion spillover may account for the linkages between workday and marital behaviors found in the study.

In the only study to examine daily links between both husbands' and wives' workday stress and marital experience, Bolger and his colleagues (Bolger et al., 1989) followed 166 married couples over 42 consecutive days. They found a daily link for men, but not for women, between self-reports of "tensions or arguments" at work and "tensions or arguments" with spouses. Husbands were more likely to report tensions with their wives on the days the husbands had experienced tensions at work. Their one-item measure of daily workload -- having "a lot of work" -- was not linked with marital tensions or arguments. Withdrawn marital behavior was not assessed in this study.

In both of these groundbreaking studies, subjective workday experiences and evening 
marital experiences were assessed simultaneously in the evening. For example, in the Bolger et al. study, participants were queried once per day about work and family experiences over the previous 24 hours. This once-per-day assessment raises concerns about retrospective distortions and introduces ambiguity about the temporal ordering between work and family experiences (Larson \& Almeida, 1999). Participants' recall of their workday experiences might have been influenced by their mood at the time of recall and the quality of their family experiences after the workday. Repetti's incorporation of wives' reports of their husbands' marital behaviors and objective indicators of daily work stress provided strong evidence that workday experiences and evening behaviors might be linked by an underlying causal process, such as spillover or role conflict, rather than by some type of confound, such as retrospective distortions. In the current study, we separated assessments of perceived workload and end-of-the-workday negative affect from evening assessments of marital behavior so that we could examine whether spouses' subjective workday experiences prospectively predict their subsequent marital behavior in the evening.

These earlier studies also point to the importance of including daily measures of end-of-theworkday affective arousal along with assessments of daily workday pace and hours worked to help clarify the extent to which emotion spillover and role conflict processes have overlapping or independent contributions to connections between daily workday experience and marital behaviors.

\section{Marital Quality and Work Status as Contexts of Gender Differences}

Gender differences in both stable patterns of marital behavior and the daily links between workday affective experiences and marital behavior may be influenced by the overall quality of the marriage. There is evidence that husbands are more likely to withdraw and wives more likely to become demanding or critical if the spouses are not satisfied with their relationship (Sagestrano et al., 1998). The meaning and consequences of particular marital behaviors are also likely to depend on the quality of the marriage. Anger expressed in a satisfying marriage may not be as likely to be reciprocated, whereas anger expressed in a less satisfying marriage may lead to escalation and even violence (Brody, 1999). Functionalist perspectives on emotion argue that the expression of anger can lead to adaptive benefits by alerting important others that something is 
not going well for the individual (e.g., Brody, 1999; Campos, Mumme, Kermoian, \& Campos, 1994). In fact, past research suggests that the expression of anger by wives leads to improvements in marital satisfaction over a three year period (Gottman \& Krokoff, 1989).

Previous research on work-family linkages indicates that contextual factors can reduce or amplify the links between workday experiences and marital functioning (e.g., Moore, Spain, \& Bianchi, 1984). Ongoing factors that influence the emotional climate of the marriage, such as marital quality, are likely to shape spillover processes within a marriage. Repetti (1989) found that wives' daily supportive behavior toward their husbands increased the tendency for husbands to respond to work stress with withdrawal, and decreased their tendency to respond with anger. In the present study, we examine the moderating impact of marital satisfaction -- a key determinant of the daily ecology of couple interactions -- on the daily connections between workday experience and marital behavior at home.

Past research on spillover of workday experiences has focused on employed work experiences. Researchers have tended to view the home as a sanctuary from which one recuperates from the unique emotional strains associated with work (Baruch, Biener, \& Barnett, 1987). This view fails to recognize how household and childrearing responsibilities during the day can precipitate stress and emotion processes similar to those experienced in work settings outside the home (Hochschild, 1997; Larson \& Richards, 1994). The workdays of mothers whose work is at home are typically excluded from studies of "work stress." In the current study, we consider the workday stress and emotional experience of both stay-at-home parents and parents working full- or part-time in the paid labor force outside the home. We examine whether links between workday experiences and marital behaviors depend on employed work status.

\section{The Current Study}

The current study uses twice-daily assessments over a three day period to explore two distinct questions about men's and women's withdrawn and angry marital behaviors. First, we investigate whether aggregated reports of nightly withdrawn and angry marital behaviors indicate that men and women typically act differently in marital interactions after the work day. Second, we investigate whether fluctuations in stressful workday experiences are prospectively linked to changes in husbands' and wives' nightly behavior within their marriage. Based on 
research that indicates that gender differences in relationship behaviors are enhanced when individuals are stressed or experiencing negative emotions, we expected to find more prominent gender differences in the linkages between workday stress and marital behavior than in typical marital behaviors.

By incorporating measures of both daily workload and end-of-the-workday negative affect as indicators of workday stress, we hope to clarify the extent to which emotion spillover and role conflict processes are responsible for daily workday-family linkages. Based on past research, we expected that both men and women would be more withdrawn from their partners after more stressful workdays. We anticipated that men would also engage in fewer angry behaviors with their wives after more stressful workdays. Because our review of the literature, especially work focusing on women's tendency to ruminate and affiliate under stress, suggested competing hypotheses about the effects of stressful workdays on women's angry marital behavior at night, we explore this question rather than make a specific hypothesis. Based on findings suggesting that men may be more reactive to negative emotional arousal, we hypothesized that men's nightly marital behaviors were more likely to vary in connection with fluctuations in negative emotional arousal at the end of each workday rather than their daily workload. By contrast, because of typically greater family role responsibilities for women, we anticipated that wives' nightly marital behavior would be more strongly linked to changes in their daily workload.

Finally, we examine how marital satisfaction is related to men's and women's typical marital behavior and their behavior following stressful workdays. We were particularly interested in investigating whether marital satisfaction moderates daily connections between workday experiences and marital behavior at the end of the day. We anticipated that more maritally satisfied men and women would be more likely than dissatisfied spouses to withdraw from their partners in response to increased workday stress. We also expected that greater marital satisfaction would be connected with men's tendency to respond to more stressful workdays with less angry marital behavior. We did not make a specific prediction regarding the role of marital satisfaction in moderating links between workday stress and women's angry marital behavior.

Method

\section{Participants}


Because nightly family routines and opportunities for marital interaction are likely to be influenced by the presence and age of children in the home, we sampled couples that were at similar stages in their family life cycle. Participants were 42 married couples with an oldest child in kindergarten that were drawn from a larger longitudinal study (see Cowan \& Cowan, 1997 for details of the larger study). Families were recruited for the larger study from preschools, child care centers, pediatricians' offices, and announcements in the media in the San Francisco Bay Area. All 50 families that had completed the first wave of the larger study were invited to participate in this study. Four couples declined to participate in this study, and three completed only 1 of the 3 days of assessments and were excluded from analyses. Data from one additional family were excluded from analyses because the husband worked a midnight to 8 A.M. shift, making it difficult to make comparisons with the evening routines of the rest of the sample.

The men and women participating in this study lived in urban and suburban areas, were employed in a variety of jobs, and were of predominantly middle class backgrounds. Eighty-five percent of the men and women in the sample described themselves as White or Caucasian and $15 \%$ described themselves as being of African American, Hispanic, Middle-Eastern, or Asian heritage. The men in the study ranged in age from 27 to 53 years (mean=38 years), the women from 27 to 46 years (mean=36 years). Twenty-six percent of the couples had only one child at the time of the current study, $69 \%$ had two children, and $5 \%$ had three children.

The men were employed an average of 43 hours per week $(S D=9.8$ hours $)$. All but one of the men were employed at least 20 hours per week $^{1}$ and 93 percent were employed 35 hours or more. The median annual income for men was $\$ 54,000(S D=\$ 37,895)$. The women varied substantially in the hours they worked outside the home each week ( $\mathrm{SD}=19.0$ hours); on average they were employed 25 hours per week. Sixty percent of the women were employed at least 20 hours per week and all but six of these women worked an average of 6 hours per day during the three days of daily data collection for this study. Seven women were not employed at the time of this study. The median annual income for women was $\$ 22,000(S D=\$ 33,108)$.

\section{Procedures}

In the first phase of data collection, participants filled out a questionnaire about the quality of their marriage along with other questionnaires and assessments that were part of the larger 
longitudinal investigation. In the second phase of data collection (average time between phases was 5 months), participants completed separate assessments of work and family experiences on each of three days. Participants were paid \$50.00 a year for completing assessments for the larger study, and no additional compensation was offered for completing the daily work and family questionnaires.

During a brief meeting at participants' homes, 3 weekdays were identified on which both partners were likely to work a typical workday and have an opportunity to interact in the evening for at least one hour. Consecutive days were chosen whenever possible. ${ }^{2}$ All participants completed questionnaires two times each day; at the end of the workday and before going to bed at night. Participants were instructed to complete their daytime report just before leaving their work sites. Wives not engaged in paid work were instructed to complete their workday reports at the time their husbands typically left work, so that these reports would be completed before the couple was reunited at home.

During the meeting at participants' homes, emphasis was placed on the importance of completing the questionnaires independently and at the designated times. To encourage participants to complete the reports at the requested times, they were asked to (a) note the time and date at the top of each questionnaire, (b) fold each questionnaire in half as soon as it was completed and seal it at the bottom with a sticker provided by the investigator, and (c) note the exact time the questionnaire was completed on the sticker. Participants were given the option of being called the night before the three-day period was to begin as a reminder to complete the questionnaires. Each partner's three days of completed reports were returned by mail.

There was an extremely high rate of compliance in completing the 6 assessments, resulting in missing data on only $1.2 \%$ of the total occasions sampled. One female participant did not fill out the daily reports on her workday. Thirty-eight of the remaining 41 men and all of the remaining women completed each of the measures at all 6 assessments.

\section{Measures}

Workday Experience. Two components of workday experience were measured each day -negative emotional arousal at the end of the workday and the perceived pace of the workday. The Negative Affectivity Scale (NAS) of the Positive and Negative Affect Schedule (PANAS -- 
Watson, Clark, \& Tellegen, 1988) consists of 10 mood adjectives that are associated with subjective distress and unpleasant arousal (e.g., irritable, distressed, nervous). Respondents were asked to characterize on a 5-point scale the extent to which they were experiencing each negative state as they ended their workday. Items were averaged to obtain a total scale score. NAS is a factor-analytically derived scale that has demonstrated good convergent and discriminate validity in previous studies (Watson et al., 1988). Previous research has shown that the NAS is useful for studying intra-individual fluctuations in mood (Watson, 1988). In this study, alpha coefficients for the NAS over the three days ranged from .86 to .92 for men and from .62 to .79 for women.

Workday Pace was measured by the Workload Scale (Repetti \& Wood, 1997), a factoranalytically derived measure consisting of five items describing the amount and pace of workload each day (e.g., "There were more demands on my time than usual"). All items refer to the day in general so that they were applicable to participants whose workdays consisted of paid work outside the home and those who were not employed outside the home during all or part of the workday. Each item was rated on a 4-point scale. The workload scale has shown a high degree of internal reliability and good concurrent and predictive validity in previous studies (Repetti \& Wood, 1997). In the current study, alpha coefficients for the workload scale ranged from .82 to .90 for men and women over the three days of data collection.

Individual Marital Behaviors. Participants reported on their own and their partner's marital behavior during the time they were at home and had an opportunity to interact as a couple in the evening. Self-reports of daytime experiences and partner reports of marital experiences -- that is, two separate sources of data -- provided a check on potential self-report biases. When filling out the evening questionnaires, participants also reported on the hours they were engaged in paid work during the day and the amount of time they spent together as a couple in the evening.

Two aspects of individual marital behavior were described by self- and partner-report each evening -- withdrawal and anger. Nightly marital behavior scales used by Repetti (1989) in her study of ATCs were adapted for this study. ${ }^{3}$ Several items were eliminated or modified from these scales to reduce participant burden and to create more independence between the withdrawn and angry behavior scales. The response format was also altered to capture the intensity with which participants engaged in the behaviors. In this study, participants were asked 
to indicate the extent to which they engaged in particular behaviors on a 4-point scale $(0=$ "not at all descriptive of my behavior or feelings," 3="I did this or felt this to a great extent"). Items were averaged to derive a total score.

The self and partner versions of the Withdrawn Marital Behavior Scale consisted of 9 items that describe disengagement from the marital relationship (e.g., "I was in my own world;" "I was withdrawn"). The partner-report contained the same items as the self-report with modifications in the wording of the stems to reflect the partner's behavior. The self and partner versions of the Angry Marital Behavior Scale consisted of 12 items that describe active expressions of angry, critical or unkind behavior (e.g., "I yelled at my partner;" "I was mean to my partner"). The modifications in the marital behavior scales resulted in greater independence between the anger and withdrawal scales than in previous research (Repetti, 1989). ${ }^{4}$

The degree of consistency between self- and partner-reports suggests that spouses agree to some extent about which behaviors were enacted each evening but that each partner had a unique perspective. Husbands' reports of their marital behavior correlated at a moderate level with wives' reports of the husbands' marital behavior (for withdrawal, $r(41)=.52, p<.01$; for anger, $r(41)=.49$, $p<.01)$. Wives' reports of their own behaviors were more weakly correlated with husbands' reports of the wives' behaviors (for withdrawal, $r(42)=.32, p<.05$; for anger, $r(42)=.38, p<.01$ ).

While there was high internal consistency in the self- and partner-reports of both marital behavior scales (see alpha coefficients reported in Appendix), HLM analyses reported below incorporated a measurement model to correct estimates for measurement error in the outcome variables (see Raudenbush et al., 1995 for details). For the measurement model, parallel scales of each marital behavior measure were created by matching pairs of items by similar levels of variance and then randomly assigning items to one of two parallel scales. Each parallel scale was the mean of the items assigned to that scale. This procedure ensured that the parallel scales for each of the marital behavior scales would have approximately the same reliability and variance.

Marital Satisfaction. The Short Marital Adjustment Test (MAT, Locke \& Wallace, 1959) is a widely used 15-item questionnaire assessing marital satisfaction that has been demonstrated to have high levels of discriminant, concurrent, and predictive validity (Gottman, 1994). Higher scores on the MAT reflect greater satisfaction with the overall marriage. 


\section{Results}

\section{Description of Study Variables and Gender Differences in Typical Marital Behaviors}

Means and standard deviations for marital satisfaction and the daily workday experience and nightly marital behavior variables aggregated over the three days of data collection are presented in Table 1. Preliminary analyses indicated substantial variation across participants, as well as variation within individuals over the three days in each of these variables. All of the variables except one were normally distributed. Husbands and wives indicated that many of the behaviors included on the angry marital behavior scale were enacted relatively infrequently or at a low level on any given night, resulting in a positively skewed distribution.

Paired-samples t-tests of both self- and partner-reports were used to investigate whether gender was linked to differences in typical levels of withdrawn or angry marital behavior. None of these four analyses yielded significant $(p<.05)$ or marginally significant $(p<.1)$ gender differences.

Correlational analyses linking the aggregated workday and evening behavior variables with marital satisfaction indicated that only husbands' withdrawal behavior was associated with marital quality. Wives who were more satisfied with their marriages reported that their husbands were less likely to be withdrawn across the three evenings, $r(42)=-.43, p=.01$. Husbands' reports of their own withdrawal were linked at a trend level with their wives' marital satisfaction $r(42)=-$ $.27, p=.08$.

\section{Data Analytic Overview of Within-Subject Analyses}

A central question in this study concerns the daily connection between workday stress and marital behavior at home. Eighty-two husbands and wives, nested within 42 couples, contributed data twice per day over three days. These data can be conceptualized at two levels of analysis: a within-couple level (Level 1), which captures daily covariation of workday experience and evening marital behavior for the husbands and wives in each couple; and a between-couple level (Level 2), which captures variability between couples in this covariation. Analyses were conducted using a hierarchical modeling approach that simultaneously models effects at the within- and between-couple levels (Raudenbush \& Bryk, 2002). Level 1 models provide separate estimates of effects for each couple. The Level 1 estimated parameters are effectively treated as 
dependent variables in the Level 2 equations to derive aggregated estimates for the sample as a whole. The maximum likelihood procedure used to estimate HLM models incorporates weighting algorithms that help improve the precision of the estimated parameters for the sample as a whole (Raudenbush \& Bryk, 2002; Kenny, Kashy, \& Bolger, 1998).

A multivariate extension of hierarchical modeling was used that permitted (1) simultaneous estimates of models for husbands and wives, with gender specific predictors and covariates, (2) direct tests for gender differences in estimated parameters, and (3) incorporation of a measurement model that took into account errors of measurement in the outcome variables when making all model estimates (see Barnett et al., 1993; Raudenbush, Brennan, \& Barnett, 1995 for details). The incorporation of this measurement model effectively means that the outcomes being predicted are the latent true scores of each marital behavior scale (Raudenbush et al., 1995).

There is an important methodological advantage to examining workday-marital behavior linkages simultaneously in husbands and wives because of the greater power to detect gender differences in married pairs than in unrelated men and women (Barnett et al., 1993). The added power comes from the ability to remove all between-family variation from the error term when examining gender differences in matched pairs. Traditional regression-based statistics assume that participants are independent of each other and, therefore, cannot efficiently compare husband and wife coefficients in matched-pairs designs.

Analyses were conducted in two stages. First, we examined whether fluctuations in daily negative affect at the end of the workday and workday pace were linked with subsequent marital behavior each night. Second, we investigated whether variations in these linkages across individuals were related to levels of marital satisfaction and hours employed outside the home. In both stages, separate models were estimated for each combination of the two workday predictors and the four marital behavior outcomes.

\section{Daily Connections between Workday Experience and Marital Behavior}

Before examining the contribution of daily changes in the workday experience variables to nightly fluctuations in withdrawn or angry marital behavior, several sets of control variables were incorporated into the model. To account for daily fluctuations in work hours and couple time in the evening, variables capturing daily deviations from the 3-day average in hours spent in 
paid work each day and with one's partner each night were entered for men and women. To control for day-to-day variability in marital behavior that might be related to changes in participants' reactions to completing the twice-daily questionnaires over the three days (e.g., boredom with the questions) or to changes in daily routines or energy levels that might relate to the day of the week, two additional sets of control variables were incorporated for men and women: two orthogonal polynomial contrasts captured linear and quadratic temporal trends in marital behavior over the 3 days of data collection (Raudenbush et al., 1995), and a series of four dummy variables identified the day of the week. ${ }^{5}$

The Level 1 model for withdrawal and end-of-the-workday negative affect (NA) can be written as:

$$
\begin{gathered}
\mathrm{WD}_{\mathrm{it}}=(\text { male }) i t\left[\pi_{\mathrm{m} 0 \mathrm{i}}+\pi_{\mathrm{m} 1 i} \text { (husband's workday NA) it }+\pi_{\mathrm{m} 2 i}\right. \text { (husband's control } \\
\text { variable } \left.\left.1)+\ldots+\pi_{\mathrm{m} 9 i} \text { (husband's control variable } 8\right)\right]+ \\
\left.(\text { female }) i t\left[\pi_{\mathrm{f} 0 \mathrm{i}}+\pi_{\mathrm{f} 1 i} \text { (wife's workday } \mathrm{NA}\right) \mathrm{it}+\pi_{\mathrm{f} 2 i} \text { (wife's control variable } 1\right)+\ldots+ \\
\left.\left.\pi_{\mathrm{f} 9} i \text { (wife's control variable } 8\right)\right]+\mathrm{e}_{i t}
\end{gathered}
$$

where $\mathrm{WD}_{\mathrm{it}}$ is the parallel marital withdrawal scale $t(\mathrm{t}=1, \ldots, 12)$ for couple $i$ ( 2 parallel scales per participant per night or 12 per couple over the 3 nights), male and female are dummy-coded variables that indicate gender, husband's and wife's workday NA are the man's and woman's daily deviation in end-of-the-workday negative affectivity from their respective three-day averages, and $\mathrm{e}_{\mathrm{it}}$ is a random error of measurement. Of particular interest are $\pi_{\mathrm{m} 1 i}$ and $\pi_{\mathrm{f}} 1 i$, which represent, respectively, the expected increase in husband $i$ 's and wife $i$ 's nightly marital withdrawal associated with a unit increase in his and her daily end-of-the-workday negative affectivity. These estimates can be conceptualized as indices of daily spillover.

Following Raudenbush et al. (1995), the six growth coefficients (including the male and female intercepts capturing individual differences in average marital withdrawal) were allowed to vary randomly in the Level 2 model, capturing all the available random variation between couples. All the additional predictors were viewed as fixed effects. In this first stage of analysis, no predictors were added to the between-subject level of the model. The Level 2 equations for the withdrawal response to workday NA for men and women can be written as:

$$
\pi_{m 1 i}=\beta_{m 10} \quad \pi_{f 1 i}=\beta_{f 10}
$$


where $\beta_{m 10}$ and $\beta_{f 10}$ represent, respectively, the pooled estimates for daily withdrawal response (spillover) to workday NA for men and women. Gender differences in the magnitude of daily spillover connections were examined by testing whether the estimated male and female Level 2 parameters for each of these constructs differed significantly from each other.

All model estimates were made using the HLM 5 computer program (version 5.04, Raudenbush et al., 2000). ${ }^{6}$ The models estimated for angry marital behavior were identical to the withdrawal models, with one exception. The skewed distribution of angry marital behavior scores did not meet the assumption of normality underlying the linear version of HLM. The distribution did approximate a poisson distribution commonly produced by count data, so models with angry marital behavior were estimated using the generalized linear modeling (HGLM) extension of HLM for count data (see Breslow \& Clayton, 1993; Raudenbush et al., 2000; Raudenbush \& Bryk, 2002). The coefficients estimated for the angry behavior outcomes are presented in logged units so that information on the direction of change in angry behavior associated with a 1-unit increase in the workday predictor can be easily interpreted (positive coefficients indicate increases in angry behavior and negative coefficients indicate decreases). The pooled spillover estimates for angry marital behavior -- $\beta_{m 10}$ and $\beta_{f 10}--$ can also be interpreted as the logged odds ratio that a 1 unit increase in the workday predictor would lead to a 1 unit increase in the marital anger scale score (Mayrent, 1987).

End-of-Workday Negative Affectivity and Nightly Marital Behavior. Results presented on the left side of Table 2 provide evidence that daily variation in husbands' and wives' end-of-theworkday mood was linked to their nightly marital behavior. Husbands reported being more withdrawn from their partners in the evenings after ending the work day feeling more negatively aroused ( $(\beta=.212, p=.04)$. Wives' withdrawal at home each evening was not linked to their negative affectivity at the end of the workday. There was consistent evidence across self- and partner-report data that both husbands' and wives' angry marital behavior in the evening shifted as a function of fluctuations in their negative affectivity at the end of the workday. The pattern of response differed distinctly by gender. On evenings after husbands had ended their workday feeling more negatively aroused, they tended to report fewer angry behaviors toward their wives ( $\beta=-.777, p=.06$ ) and their wives reported seeing the husbands behave in less angry ways ( $\beta=-$ 
$.185, p=.02)$. On evenings after wives had ended the workday feeling more negative, they tended to report that they behaved more angrily toward their husbands $(\beta=.911, p=.09)$ and their husbands tended to report that the wives displayed more angry behavior $(\beta=.387, p=.06)$.

While several of these estimated coefficients are only marginally significant, the strikingly similar pattern of results across self- and partner-reports makes it unlikely that these findings occurred by chance. Moreover, the estimated coefficients for husbands and wives for analyses using both self- and partner-report are significantly different from each other, indicating that responses did differ consistently by gender (Self-Report: $\chi^{2}[1, N=42]=6.67, p<.01$; PartnerReport: $\left.\chi^{2}[1, N=42]=8.33, p<.01\right)$. Converting the estimated coefficients to odds ratios (the antilogs of these estimates) helps highlight the magnitude of spouses' behavioral reactivity to changes in negative affectivity and of the gender difference. On days that women reported negative emotional arousal 1 unit above their average level at the end of the workday, they were 8.1 times more likely to have reported a 1-unit increase in their angry marital behaviors than on days they experienced an average level of negative emotional arousal. By contrast, on days in which men experienced negative emotional arousal 1 unit higher than average, they were 6 times more likely to have reported a 1-unit drop in angry marital behavior.

Workday Pace and Nightly Marital Behavior. Results presented on the right side of Table 2 indicate that only wives displayed evidence of a daily connection between fluctuations in workday pace and nightly marital behavior. Wives reported being more withdrawn in the evening after they experienced higher workload days $(\beta=.205, p<.01)$. The tendency for wives to withdraw after the pace of their workday increased was significantly different from that of husbands $\left(\chi^{2}[1, \mathrm{~N}=42]=7.04, p<.01\right)$, who did not show a consistent change in marital withdrawal in response to daily fluctuations in the pace of their workdays. Analyses using partner-reports indicated that neither husbands nor wives observed differences in their partners' withdrawal over the three nights that were linked to changes in the partners' daily workload.

Wives were seen by their husbands as displaying, at a trend level, more angry behavior after the wives had experienced faster paced workdays ( $\beta=.601, p=.07)$. There was no indication that changes in men's nightly angry behavior were linked with changes in the pace of their workdays. 
One of our primary interests in this study was to clarify the degree to which emotion spillover processes could account for daily workday-marital behavior connections. The inclusion in the analyses of daily controls for hours spent at work and time spent as a couple in the evening eliminated their role as potential confounds. However, the links found between negative affectivity at the end of the workday and marital behavior in the evening could potentially be due to both those variables being related to workday pace on a daily basis. To rule out this possibility, a final set of HLM analyses were conducted in which both daily workday pace and negative affectivity at the end of the workday were entered simultaneously as predictors in equation 1 . This set of analyses indicated that the links previously noted for daily negative affectivity remained unchanged after controlling for daily workday pace. Does the Quality of Marriage Shape Reactivity to Workday Experience?

In the second stage of HLM analyses, we explored whether variation across couples in linkages between daily workday experience and nightly marital behavior was related to participants' marital satisfaction. Marital satisfaction and two time-invariant control variables were added to the Level 2 equations predicting the spillover coefficients. The control variables included husbands' and wives' 3-day average on (1) hours per day spent in paid work and (2) the workday experience variable being examined. By accounting for average hours employed each day and average workday experience, the models examined the influence of marital satisfaction on daily workday-marital behavior connections, over and above the influence of differences across participants in these two variables. The inclusion of average paid work hours per day also allowed us to investigate the degree to which employment outside the home was related to variations in links between workday experience and marital behavior. The inclusion of average end-of-the-workday negative affectivity or workday pace in the equation makes it more likely that any connections between marital satisfaction and variations in daily reactivity are due specifically to satisfaction with the couple relationship and not to a more general, personalitybased neuroticism dimension (see Bolger \& Zuckerman, 1995). The expanded Level 2 equations for the spillover coefficients can be written as:

$$
\pi_{m 1 i}=\beta_{m 10}+\beta_{m 11}(\text { Marital Satisfact. })+\beta_{m 12}\left(\text { Average Workday NA) }+\beta_{m 13}\right. \text { (Average }
$$




$$
\begin{gathered}
\left.\pi f 1 i=\beta_{f 10}+\beta_{f 11}(\text { Marital Satisfact. })+\beta f 12 \text { Average Workday NA }\right)+\beta f 13 \text { (Average Work } \\
\text { Hours/Day). }
\end{gathered}
$$

Tests for gender differences in the influence of marital satisfaction on daily spillover were conducted by comparing $\beta_{m 11}$ and $\beta_{f 1} 1$.

The results presented in Table 3 provide evidence that marital satisfaction was linked with variation across couples in the likelihood of being more withdrawn or angry in marital interactions after faster paced or more negatively arousing workdays. Husbands' and wives' angry responses, in particular, were linked to the quality of the marriage as they each described it, and those links were dependent on gender. Husbands in more satisfying marriages were less likely to report increased angry behaviors after more distressing workdays ( $(=-.074, p=.08)$. Although this finding was only marginally significant, a model estimated with the wives' reports of husbands' marital behavior showed the same dampening effect of marital satisfaction on angry responses to workday distress and was statistically significant $(\beta=-.120, p=.02)$. By contrast, the husbands of wives in more satisfying marriages were more likely to report that the wives increased their angry marital behaviors after the wives experienced more distress at the end of the workday $(\beta=.112, p=.01)$. Analyses indicated that this differential moderating effect of marital satisfaction for men and women was statistically significant $\left(\chi^{2}[1, N=42]=10.80, p<\right.$ .01). A similar association was found for women and the daily link between angry marital behavior and their reports of the pace of their workday $(\beta=.043, p=.001)$. Higher marital satisfaction was also associated with greater likelihood of the wives reporting that they behaved angrily after faster paced workdays $(\beta=.043, p<.01)$.

Results presented in the top half of Table 3 indicate only one link between marital satisfaction and variation across couples in daily connections between workday experience and withdrawn marital behavior. More maritally satisfied wives were seen by their husbands as more likely to withdraw after the wives experience faster paced workdays $(\beta=.007, p=.04){ }^{7}$

For all eight HLM models that were estimated, there was no evidence that either husbands' or wives' average number of hours worked each day was related to the degree of connection between workday pace or end-of-the-workday distress and nightly marital behavior. ${ }^{8}$ 
The primary aim of this study was to examine whether the nightly interactions of married couples were influenced by their earlier workday experiences. We found that daily variations in husbands' and wives' workday pace and end-of-the-workday mood were linked to fluctuations in their nightly withdrawn and angry marital behavior. Several aspects of the study design contribute to our confidence in arguing that short-term emotion spillover processes are responsible for at least part of the daily connection between workday experience and marital behaviors at home: (1) Measurements of workday experience, including negative emotional arousal at the end of the workday, preceded the assessment of marital behavior, making it unlikely that reverse causation (family-to-workday influences) explain the connections; (2) Workday and evening marital variables were measured close to the time these experiences occurred in order to minimize retrospective biases; (3) Careful controls were incorporated to account for potentially confounding day-to-day changes in hours worked and time spent as a couple; and (4) The findings connected to end-of-the-workday mood remained unchanged when workday pace was incorporated into analyses, indicating that the links between workday mood and later marital behavior could not be explained by a common link to workday pace. Finally, for the findings examining daily connections between end-of-the-workday mood and angry marital behavior, analyses based on partner-reports of marital behavior yielded findings that were highly similar to the analyses using self-reports. The general consistency of findings across self- and partner-reports and the presence of significant associations using partner-reports makes it highly unlikely that the findings can be explained by common reporter bias.

Another aim of this study was to examine gender differences in both spillover responses and typical levels of withdrawn and angry marital behavior. Previous research suggests that gender differences in relationship behaviors may be enhanced under conditions of stress or when individuals are experiencing negative emotions (Gottman \& Levenson, 1988; Taylor, 2002; Taylor et al., 2000). The results of our study provide strong support for this perspective. No gender differences were found in husbands' and wives' typical marital behaviors using self- or partner-reports aggregated over the three nights of the study. However, clear gender differences were found in patterns of spillover and in the way marital satisfaction was related to individual differences in husbands' and wives' tendency to show particular spillover responses. The gender- 
based pattern of results, and the selective moderating effect of marital satisfaction on variations in spillover across couples, help provide a basis for fine-tuning our understanding of spillover processes. We discuss these results in more detail by considering each type of marital behavior separately.

\section{Marital Withdrawal}

There was evidence that wives but not husbands in our study withdrew from marital interactions following increases in the pace of their workday. By contrast, heightened negative emotional arousal at the end of the workday was linked to husbands' but not wives' increased withdrawal from their partners in the evening. While no other research has directly examined women's withdrawal from their partners in response to daily changes in their workday experiences, previous research on male air traffic controllers indicated that men withdrew from marital interactions in response to increases in the pace or difficulty of their workdays (Repetti, 1989; see also similar findings for mothers' withdrawal from parent-child interactions in Repetti \& Wood, 1997 and Schulz, 1997, and for fathers' withdrawal in Repetti, 1994). Repetti (1989, 1992) has suggested that this withdrawal response may help individuals return to a more comfortable, baseline state of arousal after leaving work physiologically aroused. If we assume that negative mood states may be more directly related to physiological arousal than perceptions of workday pace are, the results for the husbands in our study are consistent with Repetti's suggestion that withdrawal may be a tool to reduce arousal. Past research indicating that men may be more sensitive to the arousal associated with negative affect also may help explain the gender specific withdrawal response to end-of-the-workday mood (Gottman \& Levenson, 1988). Women's withdrawal from their husbands after reporting faster paced workdays but not after experiencing more end-of-the-workday negative affect suggests that their withdrawal may involve other short-term mechanisms beyond emotion spillover. Perhaps faster paced workdays and the performance demands that may accompany them increase perceived conflicts between work and family roles for mothers (Hochschild, 1997).

There was evidence that wives' but not husbands' level of marital satisfaction was associated with variations across couples in withdrawal responses after faster paced workdays. More maritally satisfied women were more likely to withdraw from their partners than less 
satisfied women following higher workload days. Because the direction of influence between these responses and marital satisfaction is difficult to ascertain in this study, we must be cautious in our attempts to understand the meaning of this connection. Recall that Repetti (1989) found that men tended to withdraw more after higher workload days if their wives showed more supportive behaviors at home in the evening. This would suggest that partners in satisfying relationships may provide support and encouragement that facilitates their spouses' withdrawal at home following demanding workdays. In families with young children, husbands of maritally satisfied wives may increase their share of child care or household chores, make fewer demands on their wives, or directly encourage their wives to withdraw after a particularly demanding work day (e.g., "Mommy's had a hard day and she's just going to relax right now"). Husbands may also increase their supportive behaviors, in part, as a response to wives' heightened angry and critical behaviors after faster paced workdays. Wives who have more satisfying marriages may also feel freer to withdraw from their partners after busier workdays. Considering the opposite direction of influence, it may be that over time, being able to withdraw or express anger after a busier workday contributes to women's satisfaction with marriage.

When we examined the links between marital satisfaction and the typical level of withdrawn marital behavior shown by participants in our study, we found a link only between husbands' withdrawal and wives' marital satisfaction. Women who reported lower marital satisfaction were married to men who tended to be more withdrawn each night. Since we assessed withdrawal for only three nights, we must be cautious in characterizing these patterns as indicative of chronic patterns. Nevertheless, our findings are consistent with the view that a stable tendency to withdraw from marital interactions would have more negative effects on a marriage than a tendency to become more withdrawn after more difficult workdays.

\section{Angry Marital Behavior}

Previous research has provided evidence for decreases in angry marital behavior after more difficult workdays, at least for men (Bolger et al., 1989; Repetti, 1989). The findings from our study provide additional evidence of this pattern for men but suggest the opposite response for women. In the only other study to examine daily spillover connections between workday experience and women's marital interactions, there was no evidence of a link between workday 
tensions or overloads and evening marital tensions (Bolger et al., 1989). The findings from the present study indicate that, in addition to withdrawing, men decreased their angry, critical behaviors toward their wives after ending the workday with more negative affect. By contrast, wives increased their angry, critical behavior toward their husbands following more negatively arousing or busier workdays. After busier workdays, this increased angry behavior for wives occurred along with increased withdrawal.

It is noteworthy that these gender differences were amplified for participants with greater marital satisfaction. Women in more satisfying marriages were more likely than dissatisfied women to increase their angry behavior toward their husbands after busier workdays. By contrast, men in more satisfying marriages were less likely than their maritally dissatisfied counterparts to be angrier and more critical toward their wives after negatively arousing workdays.

These gender differences in angry responses may reflect different goals in intimate relationships and different responses to negative emotional arousal. Past research suggests that men tend to disengage when negatively aroused, whereas women prefer to engage with others and talk about their distress more directly (Gottman \& Levenson, 1988; Nolen-Hoeksema, 1987, 1991; Taylor, 2002). In laboratory-based research on marital interaction, husbands displayed larger autonomic nervous system responses to conflictual discussions with their wives and recovered more slowly from this physiological arousal than wives did (Gottman \& Levenson, 1988). This gender-based physiological difference might lead men to rely more on strategies like withdrawal and avoidance of angry interactions to facilitate their recovery from negative affective arousal after a difficult workday. Women may not be compelled to "compartmentalize" their affective workday experience in this way and, in fact, may be more likely to want to engage with and talk about their stressful day with their partners. The existence of these gender patterns is supported by previous research showing that men were more likely than women to attempt to prevent their job distress from entering the marital relationship (Pearlin \& McCall, 1990).

Gender differences in angry behavior as a response to workday mood and pace may also be reflective of differences in women's and men's roles at home. Women tend to be responsible for more of the family and child-related tasks than men are (Cowan \& Cowan, 1988, 1992; 
Hochschild, 1989). This imbalance in family responsibilities is particularly likely for participants in this study who were parents of at least one child under 6 years of age. As a result of their larger family role obligations, mothers may have less freedom to vary their nightly engagement in family relationships, even after a difficult workday (Repetti, 1989). If women begin an evening after a difficult workday having to assume more of the responsibility for preparing meals, getting children bathed and ready for bed, and doing other household chores, these demands may limit the degree to which they can fully withdraw from family responsibilities, and this restriction of alternatives, in turn, could lead to an increase in angry behavior.

Most characterizations of spillover responses that involve an increase in angry behavior in response to workday stress have emphasized the negative aspects of these responses. The results of this study suggest that women's tendency to respond to workday stress with increased angry behavior toward their partners might contribute, at least over the long term, to satisfaction with the marital relationship. This interpretation would be consistent with Gottman's (1994) work on typologies of couples, in which he suggests that dealing more directly with negative affect and conflict can serve a positive function, depending on the overall relationship context in which it occurs. We must be cautious, however, in assuming that what individuals report as angry, critical behavior is the same across couples experiencing different levels of marital satisfaction. Although marital satisfaction was not correlated with typical levels of angry marital behavior across the three nights of this study, it may that the angry behavior reported by maritally satisfied women after busier workdays may differ in subtle ways from that of more maritally distressed wives (see, for example, Gottman's [1994] discussion on the differential impact of anger and contempt on marital satisfaction).

\section{Future Research}

One of the important strengths of daily diaries is the opportunity they offer to study important emotion and family processes in situ rather than in an artificial laboratory setting (Larson \& Almeida, 1999; Bennett, Schulz, Cowan, \& Cowan, 2003). This strength brings with it a great challenge -- the motivation and compliance of participants. This challenge is particularly strong for family researchers who wish to involve multiple family members in their studies. Completing repeated assessments more than once per day over multiple days puts a large 
demand on participants. In the present study, 46 of 50 couples invited to participate in this research agreed to do so, and all but 3 completed assessments on each of the days of the study. The other participants completed their daily diary questionnaires on $98.8 \%$ of the six occasions sampled. We believe that this high rate of participation and compliance, which was an important strength of this study, was facilitated by participants' involvement in the larger investigation in which this study was embedded and by their familiarity with and trust in the primary investigators from earlier phases.

Researchers using daily diary methods must carefully balance concerns about overburdening participants with the desire to obtain valid and reliable measures and sufficient variability across occasions to allow for the reliable investigation of within-subject variability. Overburdened participants are more likely to become bored or frustrated with the demands of diary studies and provide less valid data over time. Common strategies for reducing the demands on participants are to limit the number of assessments or reduce the length and complexity of diary assessments. Each of these strategies has tradeoffs. For example, the Bolger et al. (1989) study used simple, once-a-day, one-item checklists that captured only the absence or presence of workday overloads and workday or marital tensions over a 24 hour period rather than the intensity or severity of these experiences at particular points in the day. However, participants in their study completed diaries once per day over 42 consecutive days, thus providing an impressively long time series in which to investigate within-subject variation (see also Bolger, Zuckerman, \& Kessler, 2000; Thompson \& Bolger, 1999). In our study we collected two diary reports per day over a three-day period, but asked participants to complete workday and marital behavior measures with multiple items that distinguished among variations in the intensity and quality of these experiences or behaviors. We were concerned that more assessments would lead to poorer compliance and promote greater resistance to the study tasks. However, having only 3 days of data limits the degree of within-subject variability that can be observed and provides less assurance that we have captured participants' "typical" way of responding to daily workday experience. The number of daily connections found in this study between daily workday experience and subsequent marital behavior, and their lawful links to a relatively stable measure of marital satisfaction, in spite of the relatively few days assessed, suggests that these 
connections are robust.

Spillover from daily workday experience to marital behavior occurs in a larger family context in which other roles and family relationships are likely to be influenced. Simultaneous investigation of nightly variation in household task completion and both instrumental and emotional involvement with the child would help clarify the nature of spillover processes and the source of gender differences in these processes. The quality of the relationships between parents and their child and the degree to which care of the child and household chores are shared by both partners could influence nightly marital responses to workday stress.

\section{Implications for Application and Public Policy}

Balancing the daily demands of work outside the home, parenting, household tasks, and marital relationships is difficult for many men and women, particularly those with young children. Many employers have realized that these challenges have an impact on the productivity of their employees and taken steps to make their work settings more "family friendly." These steps include establishing onsite daycare facilities and offering flexible work hours in an attempt to reduce conflicts that working parents experience between job and family commitments. The results of this study suggest that work-based time conflicts are only one part of the multiple challenges that parents experience in balancing workday and marital demands. The emotional currents of the workday, whether they emanate from work or other daytime experiences, are linked to the quality of nightly marital interactions, and these linkages are somewhat different for mothers and fathers. Recognizing these gender differences can help refine future efforts to help parents and couples cope with these challenges. The findings from this study suggest that certain short-term responses to workday stress can be anticipated and that some of those responses may actually play a role in preventing workday experiences from having a long-term negative influence on marital relationships. 


\section{References}

Allen, T. D., Herst, D. E. L., Bruck, C. S., \& Sutton, M. (2000). Consequences associated with work-to-family conflict: A review and agenda for future research. Journal of Occupational Health Psychology, 5, 278-308.

Almeida, D. M., \& Kessler, R. C. (1998). Everyday stressors and gender differences in daily distress. Journal of Personality and Social Psychology, 75(3), 670-680.

Barling, J. (1990). Employment, stress and family functioning. New York: John Wiley and Sons.

Barnett, R.C., Marshall, N.L., Raudenbush, S.W., \& Brennan, R.T. (1993). Gender and the relationship between job experiences and psychological distress: A study of dual-earner couples. Journal of Personality and Social Psychology, 64, 794-806.

Bennett, A., Schulz, M.S., Cowan, P.A., \& Cowan, C.P (2003). The long and short of parenting stress: Daily and longer-term emotional consequences of tension in parent-child interactions. Manuscript submitted for publication.

Baruch, G.K., Biener, L., \& Barnett, R.C. (1987). Women and gender in research on work and family. American Psychologist, 42, 130-136.

Bolger, N., DeLongis, A., Kessler, R.C., \& Wethington, E. (1989). The contagion of stress across multiple roles. Journal of Marriage and the Family, 51, 175-183.

Bolger, N. \& Zuckerman, A. (1995). A framework for studying personality in the stress process. Journal of Personality and Social Psychology, 69, 890-902.

Brennan, R. T., Barnett, R. C., \& Gareis, K. C. (2001). When she earns more than he does: A longitudinal study of dual-earner couples. Journal of Marriage and the Family, 63, 168-182.

Breslow, N. \& Clayton, D.G. (1993). Approximate inference in generalized linear mixed models. Journal of the American Statistical Association, 88, 9-25.

Brody, L. (1999). Gender, emotion and the family. Cambridge, MA: Harvard University Press. Campos, J. J., Mumme, D. L., Kermoian, R., \& Campos, R. G. (1994). A functionalist perspective on the nature of emotion. In N. A. Fox (Ed.), The Development of Emotion Regulation: Biological and Behavioral Considerations (Vol. 59, pp. 284-303). Chicago: University of Chicago Press. 
Caspi, A., Bolger, N., \& Eckenrode, J. (1987). Linking person and context in the daily stress process. Journal of Personality and Social Psychology, 52, 184-95.

Christensen, A., \& Heavey, C.L. (1990). Gender and social structure in the demand/withdraw pattern of marital conflict. Journal of Personality and Social Psychology, 59, 73-81.

Cowan, C.P., \& Cowan, P.A. (1997). Working with couples during stressful life transitions. In S. Dremen (Ed.), The family on the threshold of the 21st century: Trends and implications (pp. 17-47). Mahwah, NJ: Erlbaum.

Cowan, C.P., \& Cowan, P.A. (1992). When partners become parents: The big life change for couples. New York: Basic Books.

Cowan, C.P., \& Cowan, P.A. (1988). Who does what when partners become parents: Implications for men, women, and marriage. Marriage and Family Review, 13, 1-12.

Crouter, A.C., Perry-Jenkins, M., Huston, T.L., \& Crawford, D.W. (1989). The influence of work-induced psychological states on behavior at home, Basic and Applied Social Psychology, 10, 273-292.

Cummings, E.M., \& Davies, P.T. (1994). Children and marital conflict: The impact of family dispute and resolution. New York: Guilford Press.

DeLongis, A., Folkman, S., \& Lazarus, R.S. (1988). The impact of daily stress on health and mood: Psychological and social resources as mediators. Journal of Personality and Social Psychology, 54, 486-495.

Eckenrode, J. (1984). Impact of chronic and acute stressors on daily reports of mood. Journal of Personality and Social Psychology, 46, 907-18.

Gottman, J.M. (1994). What predicts divorce? Hillsdale, NJ: Erlbaum.

Gottman, J. M., \& Krokoff, L. (1989). Marital interaction and marital satisfaction: A longitudinal view. Journal of Consulting and Clinical Psychology, 57, 47-52.

Gottman, J.M., \& Levenson, R.W. (1988). The social psychophysiology of marriage. In P. Noller \& M.A. Fitzpatrick (Eds.), Perspectives on marital interaction. Philadelphia: Multilingual Matters.

Gray, J. (1992). Men are from Mars, women are from Venus:A practical guide to improving communication and getting what you want in your relationships. New York: Harper Collins. 
Hochschild, A. (1989). The second shift: Working parents and the revolution at home. New York: Viking.

Hochschild,A.R. (1997). The time bind. New York: Metropolitan Books.

Hughes, D., Galinsky, E., \& Morris, A. (1992). The effects of job characteristics on marital quality: Specifying linking mechanisms. Journal of Marriage and the Family, 54, 31-42.

Kenny, D.A., Kashy, D.A., \& Bolger, N. (1998). Quantitative methods in social psychology. In D. Gilbert, S. Fiske, \& G. Lindzey (Eds.), Handbook of social psychology (4th ed., pp.233265). New York: McGraw-Hill.

Larsen, R.J., \& Kasimatis, M. (1991). Day-to-day physical symptoms: Individual differences in the occurrence, duration, and emotional concommitants of minor daily illnesses. Journal of Personality, 59, 387-423.

Larson, R. W., \& Almeida, D. M. (1999). Emotional transmission in the daily lives of families: A new paradigm for studying family process. Journal of Marriage and the Family, 61, 5-20.

Larson, R. \& Richards, M. (1994). Divergent realities: The emotional lives of mothers, fathers and adolescents. New York: Basic Books.

Locke, H. \& Wallace, K. (1959). Short marital adjustment and prediction tests: Their reliability and validity. Marriage and Family Living, 21, 251-255.

Mayrent, S.L. (1987). Epidemiology in medicine. Boston: Little, Brown, \& Co.

Moore, K., Spain, D. \& Bianchi, S. (1984). Working wives and mothers. Marriage and Family Review, 7, 77-98.

Nolen-Hoeksema, S. (1987). Sex differences in unipolar depression: Evidence and theory. Psychological Bulletin,_101, 259-282.

Nolen-Hoeksema, S. (1991). Sex differences in responses to depression. Paper presented at the meeting of the American Psychological Association, San Francisco, CA.

Pearlin, L.I. \& McCall, M.E. (1990). Occupational stress and marital support: A description of microprocesses. In J. Eckenrode \& S. Gore (Eds.), Stress between work and family. New York: Plenum Press. 
Raudenbush, S.W., Brennan, R.T., \& Barnett, R.C. (1995). A multivariate hierarchical model for studying psychological change with married couples. Journal of Family Psychology, 9, 161174.

Raudenbush, S.W. \& Bryk, A.S. (2002). Hierarchical linear models (2nd edition), Thousand Oaks, CA: Sage Publications.

Raudenbush, S.W., Bryk, A.S., Cheong, Y.F., \& Congdon, R.T. (2000). HLM 5: Hierarchical linear and nonlinear modeling. Lincolnwood, IL: Scientific Software.

Repetti, R.L. (1987). Linkages between work and family roles. In S. Oskamp (Ed.), Applied social psychology annual: Vol. 7, Family Processes and Problems. Beverly Hills, CA: Sage.

Repetti, R.L. (1989). Effects of daily workload on subsequent behavior during marital interaction: The roles of social withdrawal and spouse support. Journal of Personality and Social Psychology, 57, 651-659.

Repetti, R.L. (1992). Social withdrawal as a short-term coping response to daily stressors. In H. Friedman (Ed.), Hostility, coping and health (pp. 151-165). Washington, DC: APA.

Repetti, R.L. (1994). Short-term and long-term processes linking job stressors to father-child interaction. Social Development, 3, 1-15.

Repetti, R.L. \& Wood, J. (1997). The effects of daily stress at work on mothers' interactions with preschoolers. Journal of Family Psychology, 11, 90-108.

Sagestrano, L. M., Christensen, A., \& Heavey, C. L. (1998). Social influence techniques during marital conflict. Personal Relationships, 5, 75-89.

Schulz, M.S. (1997). Daily linkages between parents' stressful work experiences and the quality of parent-child interactions. Paper presented at the Biennial Meetings of the Society for Research in Child Development, Washington, D.C., April, 1997.

Smith, R.E., Leffingwell, T.R., \& Ptacek, J.T. (1999). Can people remember how they coped? Factors associated with discordance between same-day and retrospective reports. Journal of Personality and Social Psychology, 76(6), 1050-1061.

Stone, A.A., \& Neale, J.M. (1984). The effects of severe daily events on mood. Journal of Personality and Social Psychology, 46, 137-145. 
Tannen, D. (1990). You just don't understand: Women and men in conversation. New York: William Morrow.

Taylor, S. E. (2002). The tending instinct. New York: Times Books.

Taylor, S. E., Klein, L. C., Lewis, B. P., Gruenewald, T. L., Gurung, R. A. R., \& Updegraff, J. A. (2000). Biobehavioral responses to stress in females: Tend-and-befriend, not fight-or-flight. Psychological Review, 107, 411-429.

Thomas, S., Albrecht, K., \& White, P. (1984). Determinants of marital quality in dual-career couples. Family Relations, 33, 513-521.

Timmers, M., Fischer, A. H., \& Manstead, A. S. R. (1998). Gender differences in motives for regulating emotions. Personality and Social Psychology Bulletin, 24, 974-985.

Watson, D. (1988). Intraindividual and interindividual analyses of positive and negative affect: Their relation to health complaints, perceived stress, and daily activities. Journal of Personality and Social Psychology, 54, 1020-1030.

Watson, D., Clark, L.A., \& Tellegen, A. (1988). Development and Validation of Brief Measures of Positive and Negative Affect: The PANAS scales. Journal of Personality and Social Psychology, 54, 1063-1070.

Weiss, R.L., \& Perry, B.A. (1983). The spouse observation checklist: Development and clinical applications. In E.E. Filsinger (Ed.), Marriage and family assessment: A sourcebook for family therapy. Beverly Hills, CA: Sage. 


\section{Appendix}

\section{Marital Behavior Scales}

\section{Withdrawn Marital Behavior Scale}

1. I was in my own worlda

2. I wanted to be alonea

3. I wanted some quiet time to myselfa

4. I avoided talking about problems we were having $b$

5. I did not feel like talking about my feelings or thoughts with my partnerb

6. I avoided listening to my partner's feelings $b$

7. I found it hard to unwind at homed

8. I was talkative (reverse scored) ${ }^{\mathrm{d}}$

9. I was withdrawnd

Angry Marital Behavior Scale

1. I took out my frustrations on my partnera

2. I yelled at my partnera

3. I was impatient ${ }^{\mathrm{a}}$

4. I was argumentative ${ }^{b}$

5. I complained about things my partner did or things he/she did not doc

6. I got angry at my partner ${ }^{\mathrm{c}}$

7. I said unkind things to my partnerc

8. I was sarcastic to or made fun of my partner in a way that was not nicec

9. I was mean to my partnerd

10. I became annoyed with my partnerd

11. I acted in an unkind manner to my partnerd

12. I snapped at or spoke in a nasty tone of voice to my partnerd 
Note. For withdrawn marital behavior, husbands' mean alpha over the 3 days for self report $=.84$; husbands' mean partner report alpha=.76; wives' mean self report alpha=.74; wives' mean partner report alpha=.76. For angry marital behavior, husbands' mean alpha over the 3 days for self report=.91; husbands' mean partner report alpha=.88; wives' mean self report alpha=.83; wives' mean partner report alpha $=.88$.

$\mathrm{a}$ item taken from Repetti (1989) $\quad \mathrm{b}$ item adapted from Repetti (1989) $\quad \mathrm{c}$ item adapted from Repetti (1989), originally created by Weiss and Perry (1983) d item created for this study. 


\begin{abstract}
Author Note
Marc S. Schulz, Department of Psychology, Bryn Mawr College; Philip A. Cowan and Carolyn P. Cowan, Department of Psychology and Institute of Human Development, University of California, Berkeley; Robert T. Brennan, Graduate School of Education, Harvard University. This research was supported by a grant from the Spring Foundation and the Sheldon Korchin Prize from UC Berkeley to Marc S. Schulz, and NIMH Grant MH-31109 to Philip A. Cowan and Carolyn P. Cowan. We wish to acknowledge Rena Repetti, Sheldon Zedeck, Barry Staw, Jeffrey Measelle, Robert Waldinger, and Stacy Miller for their helpful suggestions and assistance.
\end{abstract}

Correspondence concerning this article should be addressed to Marc S. Schulz, Department of Psychology, 101 North Merion Avenue, Bryn Mawr College, Bryn Mawr, PA 19010. 


\section{Footnotes}

1 Because this man was the only man in the sample who did not engage in paid work, we decided not to examine his workday experience reports and marital behavior in this study. His reports of his wife's nightly marital behavior were included in analyses.

${ }^{2}$ For 38 of 42 couples, the 3 days were consecutive.

3 Some of the items on Repetti's scales were originally derived from Weiss and Perry's (1983) Spouse Observation Checklist.

${ }^{4}$ Participants' 3-day averages on the angry and withdrawn marital behavior scales were correlated with each other, but at a lower level than in previous research (Men: self-reports $r$ $(41)=.33, p<.05$; partner-report, $r(41)=.24, p<.1$; Women: self-report, $r(42)=.37 ; p<.01$; partnerreport, $r(42)=.35, p<.05)$.

${ }^{5}$ Preliminary analyses confirmed that quadratic terms were necessary because the Level 2 variances of the quadratic effects for men and women were significantly greater than zero.

6 The more conservative fixed effects estimates without robust standard errors were used because larger samples sizes are generally recommended for approaches with robust standard errors (Raudenbush \& Bryk, 2002).

${ }^{7}$ An additional set of exploratory analyses were conducted to examine potential confounding variables that might be responsible for the moderating influence of marital satisfaction on connections between workday experiences and marital behavior. Parental age, number of children, and proportion of family income earned were incorporated as additional predictors in the Level 2 models outlined in equation 3 and presented in Table 3. The inclusion of these additional Level 2 predictors either had no appreciable impact on or increased the magnitude of the 16 parameters estimating the moderating effect of marital satisfaction. These results indicate that the moderating effect of marital satisfaction is not due to a confound with any of these additional predictor variables.

${ }^{8}$ The same set of analyses were carried out for the 21 couples in which the wives worked at least an average of 6 hours per day. The results of these analyses were highly similar to those presented in Table 2 and provide further evidence that work status was not systematically linked to daily connections between workday experiences and marital behavior. 
Coming home upset 38

Table 1

Means and Standard Deviations for Aggregated Workday and Evening Variables and for Marital Satisfaction

\begin{tabular}{|c|c|c|}
\hline & $\underline{\text { Husbands }}$ & $\underline{\text { Wives }}$ \\
\hline & $\mathrm{M}(\mathrm{SD})$ & $\mathrm{M}(\mathrm{SD})$ \\
\hline \multicolumn{3}{|l|}{ Workday Experience } \\
\hline End-of-Workday Negative Affectivity & $1.31(.29)$ & $1.28(.20)$ \\
\hline Workday Pace & $2.47(.59)$ & $2.42(.59)$ \\
\hline \multicolumn{3}{|l|}{ Evening Marital Behavior } \\
\hline \multicolumn{3}{|l|}{ Withdrawn } \\
\hline Self-Report & $.66(.34)$ & $.56(.29)$ \\
\hline Partner-Report & $.58(.32)$ & $.58(.30)$ \\
\hline \multicolumn{3}{|l|}{ Angry } \\
\hline Self-Report & $.18(.22)$ & $.17(.17)$ \\
\hline Partner-Report & $.13(.16)$ & $.18(.20)$ \\
\hline Marital Satisfaction & $112.4(19.0)$ & $111.9(20.4)$ \\
\hline
\end{tabular}


Coming home upset 39

Table 2

Estimates of daily spillover: Linkages between changes in daily workday experience and nightly marital behavior

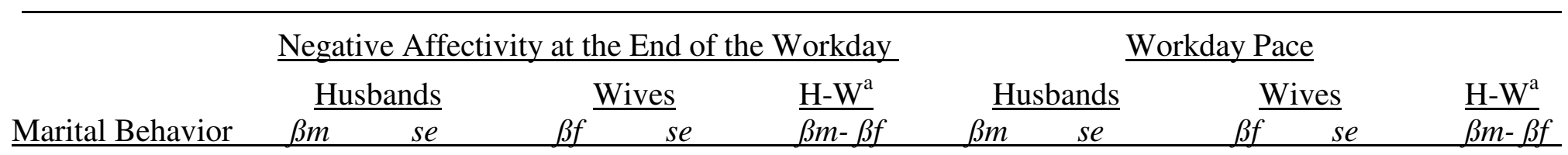

\section{Withdrawn}

$\begin{array}{lllllllllll}\text { Self-report } & .212^{*} & .105 & .077 & .151 & .135 & -.064 & .076 & .205^{* *} & .066 & -.269^{* *} \\ \text { Partner-report } & -.048 & .086 & -.116 & .146 & .068 & .080 & .080 & .037 & .072 & .043\end{array}$

Angry

$\begin{array}{lllllllllll}\text { Self-report } & -.777^{+} & .409 & .911^{+} & .534 & 1.688^{* *} & .526 & .351 & .151 & .291 & .375 \\ \text { Partner-report } & -1.185^{*} & .502 & 1.387^{+} & .734 & 2.572^{* *} & -.135 & .352 & .602^{+} & .327 & -.737\end{array}$

Note. Estimated coefficients for angry marital behavior are in logged units. All estimates are unstandardized and were calculated after controlling for daily deviations from the 3-day average of time spent working in paid employment and time spent with one's partner in the evening, day of the week, and linear and quadratic trends in the marital outcome over the 3 days.

${ }^{a}$ Difference between husbands and wives' coefficients.

${ }^{+} p<.05 . * p<.05 . * * p<.01$. 
Coming home upset 40

Table 3

Estimates of the moderating influence of marital satisfaction on daily spillover connections

\begin{tabular}{|c|c|c|c|c|c|c|c|c|}
\hline \multirow[b]{3}{*}{ Marital Behavior } & \multicolumn{4}{|c|}{ Negative Affectivity at the End of the Workday } & \multicolumn{4}{|c|}{ Workday Pace } \\
\hline & \multicolumn{2}{|c|}{$\underline{\text { Husbands }}$} & \multicolumn{2}{|c|}{$\underline{\text { Wives }}$} & \multicolumn{2}{|c|}{$\underline{\text { Husbands }}$} & \multicolumn{2}{|c|}{$\underline{\text { Wives }}$} \\
\hline & $\beta$ & se & $\beta$ & se & $\beta$ & se & $\beta$ & se \\
\hline \multicolumn{9}{|l|}{ Withdrawn } \\
\hline self-report & -.003 & .009 & -.008 & .008 & -.003 & .006 & .001 & .003 \\
\hline partner-report & -.004 & .007 & -.002 & .009 & -.002 & .005 & $.007 *$ & .003 \\
\hline \multicolumn{9}{|l|}{ Angry } \\
\hline self-report & $-.074^{+}$ & .043 & -.012 & .036 & .011 & .029 & $.043 *$ & .013 \\
\hline partner-report & $-.120 * \mathrm{a}$ & .052 & $.112 *$ & .045 & .027 & .032 & .011 & .014 \\
\hline
\end{tabular}

Note. Estimated coefficients for the effect of marital satisfaction on daily workday stress-anger linkages are in logged units. All estimates are unstandardized and were calculated after controlling for the 3-day average of the workday experience variable of interest and the 3-day average number of hours spent each day in paid employment.

a Significantly different from the comparable female coefficient $(p<.01)$.

${ }^{+} p<.05 .{ }^{*} p<.05$. 
Because this man was the only man in the sample who did not engage in paid work, we decided not to examine his workday experience reports and marital behavior in this study. His reports of his wife's nightly marital behavior were included in analyses.

${ }^{2}$ For 38 of 42 couples, the 3 days were consecutive.

3 Some of the items on Repetti's scales were originally derived from Weiss and Perry's (1983) Spouse Observation Checklist.

${ }^{4}$ Participants' 3-day averages on the angry and withdrawn marital behavior scales were correlated with each other, but at a lower level than in previous research (Men: self-reports $\underline{\mathrm{r}}(41)=.33, \underline{\mathrm{p}}<.05$; partner-report, $\underline{\mathrm{r}}(41)=.24, \underline{\mathrm{p}}<.1$;

Women: self-report, $\underline{\mathrm{r}}(42)=.37 ; \underline{\mathrm{p}}<.01$; partner-report, $\underline{\mathrm{r}}(42)=.35, \underline{\mathrm{p}}<.05)$. 